\title{
Metal stable isotopes track the fate of rock-derived nutrients in the critical zone
}

\author{
JULIEN BOUCHEZ ${ }^{1}$, FRIEDHELM VON \\ BLANCKENBURG $^{2}$ AND DR. PATRICK J. FRINGS ${ }^{2}$
}

${ }^{1}$ Institut de Physique du Globe de Paris

${ }^{2}$ GFZ German Research Centre for Geosciences

Presenting Author: bouchez@ipgp.fr

The conversion of rock into soil results in the delivery of nutrients such as phosphorus, calcium, magnesium or potassium, to the critical zone. These nutrients are intensely used by plants for their growth, but their removal as organic particles during litter erosion constitutes a net loss for ecosystems [1,2], which has to be compensated for by the supply of "new" nutrients through mineral weathering [3]. Here we show how the stable isotope ratios of metal and metalloids - many of which are rockderived nutrients - can be used to quantify such nutrient loss from ecosystems, as well as incorporation into secondary weathering phases such as clays, export as primary minerals, or export as dissolved species. We then present a comprehensive geochemical dataset measured in different critical zone compartments along three field sites of increasing erosion rate all underlain by granitoid rock types. We develop a series of elemental metrics that yield entirely independent estimates of critical zone nutrient partitioning. We use these to "groundtruth" isotope-derived fluxes for the magnesium $[1,4]$, strontium, and silicon systems against elemental metrics. In doing so, we emphasize the importance of biomass erosion as a nutrient loss pathway, and demonstrate the utility of metal and metalloid isotopes as tracers of critical zone fluxes.

[1] Uhlig D. et al., Biogeosci. 14:3111-3128, 2017; [2] Charbonnier Q. et al., Biogeosci. 17:5989-6015, 2020; [3] Uhlig and von Blanckenburg, Frontiers Earth Sci. 7:159, 2019; [4] Schuessler J.S. et al., Chem. Geol. 497:74-87, 2018. 